\title{
Clinical Role of Atrial Arrhythmias in Patients With Arrhythmogenic Right Ventricular Dysplasia
}

\author{
Ardan M. Saguner, MD; Sabrina Ganahl, MD; Andrea Kraus, PhD; Samuel H. Baldinger, MD; \\ Argelia Medeiros-Domingo, MD; Arhan R. Saguner; Stephan A. Mueller-Burri, MD; \\ Thomas Wolber, MD; Laurent M. Haegeli, MD; Nazmi Krasniqi, MD; Felix C. Tanner, MD; \\ Jan Steffel, MD; Corinna Brunckhorst, MD; Firat Duru, MD
}

\begin{abstract}
Background: The clinical role of atrial fibrillation/atrial flutter (AF-AFI) and variables predicting these arrhythmias are not well defined in patients with arrhythmogenic right ventricular dysplasia (ARVD). We hypothesized that transthoracic echocardiography (TTE) and 12-lead electrocardiography (ECG) would be helpful in predicting AF-AFI in these patients.
\end{abstract}

\begin{abstract}
Methods and Results: ECGs and TTEs of 90 patients diagnosed with definite or borderline ARVD (2010 Task Force Criteria) were analyzed. Data were compared in (1) patients with AF-AFI and (2) all other patients. A total of $18(20 \%)$ patients experienced AF-AFI during a median follow-up of 5.8 years (interquartile range 2.0-10.4). KaplanMeier analysis revealed reduced times to AF-AFI among patients with echocardiographic RV fractional area change $<27 \%(P<0.001)$, left atrial diameter $\geq 24.4 \mathrm{~mm} / \mathrm{m}^{2}$ (parasternal long-axis, $\left.P=0.001\right)$, and right atrial short-axis diameter $\geq 22.1 \mathrm{~mm} / \mathrm{m}^{2}$ (apical 4-chamber view, $P=0.05$ ). From all $E C G$ variables, $P$ mitrale conferred the highest hazard ratio (3.37, 95\% confidence interval 0.92-12.36, $\mathrm{P}=0.067$ ). Five patients with $\mathrm{AF}-\mathrm{AFI}$ experienced inappropriate implantable cardioverter-defibrillator (ICD) shocks compared with 4 without $A F-A F I(36 \%$ vs. $9 \%, P=0.03)$. AF-AFI was more prevalent in heart-transplant patients and those who died of cardiac causes $(56 \%$ vs. $16 \%, P=0.014)$.
\end{abstract}

Conclusions: AF-AFI is associated with inappropriate ICD shocks, heart transplantation, and cardiac death in patients with ARVD. Evidence of reduced RV function and atrial dilation helps to identify the ARVD patients at increased risk for AF-AFI. (Circ J 2014; 78: 2854-2861)

Key Words: Arrhythmogenic right ventricular dysplasia; Atrial fibrillation; Atrial flutter; Cardiomyopathy

A rrhythmogenic right ventricular dysplasia (ARVD) is a hereditary cardiomyopathy characterized by fibrofatty infiltration of the right ventricle (RV). ${ }^{1}$ Besides ventricular tachyarrhythmias and heart failure that may eventually lead to heart transplantation or cardiac death, ${ }^{2-4}$ spontaneous occurrence of sustained atrial arrhythmias has been recognized as a common clinical entity in ARVD, with up to $42 \%$ of patients being affected. ${ }^{5}$ Atrial fibrillation/atrial flutter (AFAFl) have long been associated with an increased risk of morbidity and mortality in the general population, ${ }^{6,7}$ but the clinical role of these atrial arrhythmias, and the clinical variables predicting AF-AFl in particular, are not well defined in patients with ARVD. ${ }^{5,8-10}$ Other than the study by Camm et al, ${ }^{10}$ all previous studies have been constrained by small sam- ple sizes and inclusion of patients with advanced ARVD.,5,9 Moreover, atrial enlargement was not well defined in any of the studies, and none of them investigated the role of 12-lead surface ECG and RV function to predict AF-AFl. Thus, the purpose of the present study was to identify the electrocardiographic and echocardiographic variables that predict AF-AFl, and to investigate the clinical role of $\mathrm{AF}-\mathrm{AFl}$ in a large cohort of patients with ARVD.

\section{Methods}

\section{Study Population}

The study population included 90 patients from 3 tertiary-care centers in Switzerland who had either a definite or a borderline

Received May 1, 2014; revised manuscript received September 3, 2014; accepted September 8, 2014; released online October 20,2014 Time for primary review: 14 days

Department of Cardiology, University Heart Center Zurich, Zurich (A.M.S., S.G., A.M.-D., A.R.S., T.W., L.M.H., N.K., F.C.T., J.S., C.B., F.D.); Division of Biostatistics, Institute for Social and Preventive Medicine, University Zurich, Zurich (A.K.); Department of Cardiology, University Hospital Bern, Bern (S.H.B., A.M.-D.); Department of Cardiology, Triemli Hospital Zurich, Zurich (S.A.M.-B.); and Center for Integrative Human Physiology, University Zurich, Zurich (T.W., F.C.T., F.D.), Switzerland

Mailing address: Firat Duru, Professor, MD, Department of Cardiology, University Heart Center Zurich, Rämistrasse 100, CH-8091 Zurich, Switzerland. E-mail: firat.duru@usz.ch

ISSN-1346-9843 doi:10.1253/circj.CJ-14-0474

All rights are reserved to the Japanese Circulation Society. For permissions, please e-mail: cj@j-circ.or.jp 


\begin{tabular}{|c|c|}
\hline Variable & Definition \\
\hline$P$ wave duration (Pmax) & $\begin{array}{l}\text { Longest interval between the earliest onset of the wave (positive deflection } \\
\text { crossing the isoelectric line) and the latest off-set in any of } 12 \text { leads }\end{array}$ \\
\hline P wave dispersion & Difference between Pmax and minimal P duration \\
\hline Notched P wave & P wave "notched" if interpeak duration in the limb leads $\geq 40 \mathrm{~ms}$ \\
\hline P mitrale & $\begin{array}{l}\text { 1) } P \text { wave in any lead }>110 \mathrm{~ms} \text { and } \\
\text { 2) Notched } P \text { wave with interpeak duration } \geq 40 \mathrm{~ms} \text {, } \\
\text { 3) } P \text { wave axis }<30^{\circ} \text {, or } \\
\text { 4) Positive } P \text { terminal force in aVL }>0.5 \mathrm{~mm}\end{array}$ \\
\hline P pulmonale & $P$ wave voltage $\geq 0.25 \mathrm{mV}$ in any inferior lead or positive $P$ wave in $V 1>1.5 \mathrm{~mm}$ \\
\hline RV FAC (\%) & RV [Area D-Area S]/Area D measured in the apical 4CV \\
\hline RA short axis (mm) & $\begin{array}{l}\text { RA short-axis diameter measured in the apical } 4 \mathrm{CV} \\
\text { All atrial diameters were measured at end-ventricular systole }\end{array}$ \\
\hline RA long axis (mm) & RA long-axis diameter measured in the apical $4 \mathrm{CV}$ \\
\hline RA dilation & RA short-axis diameter $>25 \mathrm{~mm} / \mathrm{m}^{2}$ or long-axis diameter $\geq 30 \mathrm{~mm} / \mathrm{m}^{2}$ \\
\hline LA long axis $(\mathrm{mm})$ & LA diameter measured in the PLAX with M-mode (leading-edge to leading-edge) \\
\hline LA dilation & LA diameter $>23 \mathrm{~mm} / \mathrm{m}^{2}$ \\
\hline Significant TR & Moderate-to-severe $\mathrm{TR}^{19,33}$ \\
\hline
\end{tabular}

Area $D$, right ventricular end-diastolic area; Area S, right ventricular end-systolic area; 4CV, 4-chamber view; FAC, fractional area change; LA, left atrial; PLAX, parasternal long axis; RA, right atrial; RV, right ventricular; TTE, transthoracic echocardiography; TR, tricuspid regurgitation.
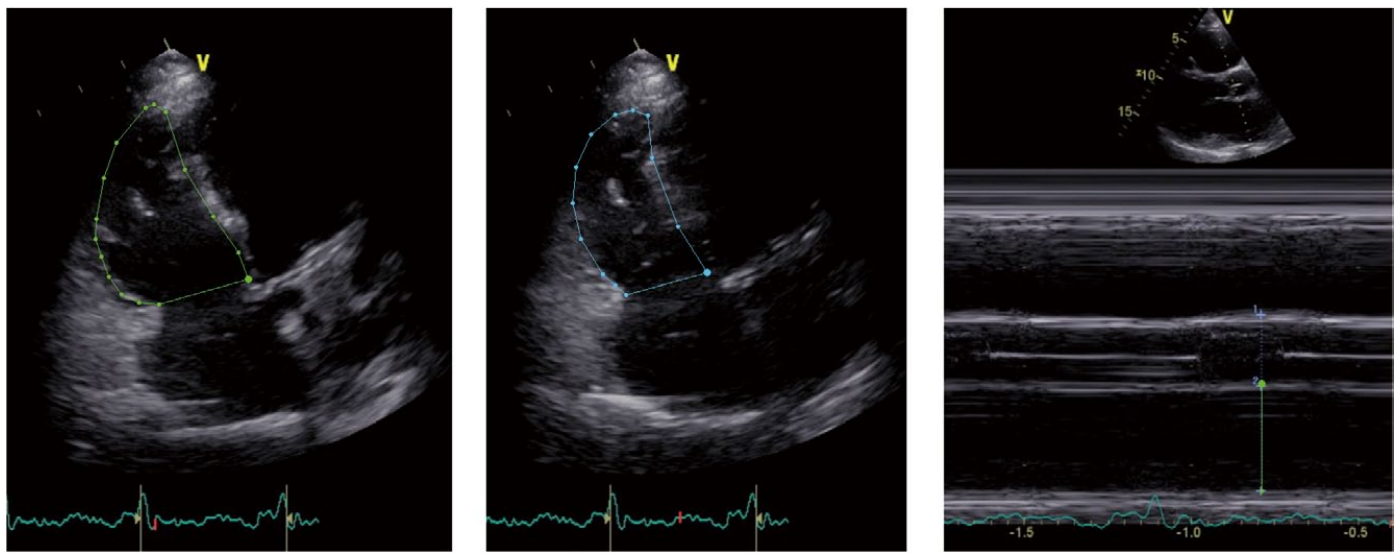

Figure 1. (Left) Representative echocardiographic RV end-diastolic area (in green). (Middle) Representative echocardiographic RV end-systolic area (in blue), both taken from the apical four-chamber view in a patient with definite ARVD. RV end-diastolic area was $48.5 \mathrm{~cm}^{2}$, and RV end-systolic area was $38.9 \mathrm{~cm}^{2}$, resulting in an impaired RV fractional area change of $20 \%$. (Right) M-mode measurement of LA dimension in ventricular end-systole in the parasternal long axis in the same patient (green line). The blue dashed line indicates the aortic root diameter. The LA was dilated at $54 \mathrm{~mm}\left(25.6 \mathrm{~mm} / \mathrm{m}^{2}\right)$. ARVD, arrhythmogenic right ventricular dysplasia; LA, left atrial; RV, right ventricular.

diagnosis of ARVD according to the 2010 Task Force Criteria, ${ }^{11}$ who had an ECG recorded between February 1987 and April 2012, and for whom outcome data were available. The ECG constituted the earliest ECG available for analysis performed at one of the participating centers, and marked the starting point for study inclusion and follow-up analyses. None of the patients had had AF-AFl documented prior to study inclusion. In this observational study, patients were enrolled both prospectively $(n=11)$ and retrospectively $(n=79)$. All patients were participants in the multicenter Zurich ARVD Registry (www.arvc.ch). Clinical information regarding demographics and symptoms was obtained from hospital records. The study complied with the Declaration of Helsinki. Inclusion in this registry was approved by the institutional review boards of each participating center.

\section{Definitions of Electrocardiographic and Echocardiographic Parameters}

The ECG and transthoracic echocardiographic (TTE) definitions and criteria used in this study are presented in Table $\mathbf{1 .}$

\section{ECG Analysis}

ECGs were recorded at rest $(25 \mathrm{~mm} / \mathrm{s}, 10 \mathrm{~mm} / \mathrm{mV}$ amplitude) with standard lead positions, digitized with a high-resolution scanner, and analyzed with a digital caliper (Iconico; screen caliper version 4.0). ${ }^{12}$ To increase the accuracy of measurements, 
Table 2. Baseline Clinical Characteristics of Patients With Arrhythmogenic RV Dysplasia

\begin{tabular}{|c|c|c|c|c|}
\hline Characteristic & $\begin{array}{l}\text { All patients } \\
(n=90)\end{array}$ & $\begin{array}{c}\text { Atrial arrhythmia } \\
(n=18)\end{array}$ & $\begin{array}{l}\text { No atrial arrhythmia } \\
\qquad(n=72)\end{array}$ & $P$ value \\
\hline Age at study inclusion (years) & $44.2 \pm 14.6$ & $47.8 \pm 13.4$ & $43.3 \pm 14.9$ & 0.24 \\
\hline Age at last follow-up (years) & $49.7 \pm 14.6$ & $54.1 \pm 3.3$ & $48.7 \pm 1.7$ & 0.16 \\
\hline Male & $57(63)$ & $11(61)$ & $46(64)$ & 1.0 \\
\hline Systolic BP (mmHg) & $120(110-128)$ & $118.5(110-120.5)$ & $120(110-118)$ & 0.15 \\
\hline Diastolic BP (mmHg) & $76 \pm 9$ & $75 \pm 8$ & $77 \pm 9$ & 0.51 \\
\hline Heart rate (beats $/ \mathrm{min}$ ) & $65.2(55.1-77.2)$ & $67.2(58.4-82.4)$ & $65.2(54.3-73.2)$ & 0.19 \\
\hline $\operatorname{BSA}\left(m^{2}\right)$ & $1.9(1.7-2)$ & $1.9(1.8-2.0)$ & $1.9(1.7-2.0)$ & 0.8 \\
\hline Body mass index $\left(\mathrm{kg} / \mathrm{m}^{2}\right)$ & $24.5(22-26.5)$ & $24.5(21.8-27.3)$ & $24.6(22-26.3)$ & 0.85 \\
\hline Previous sustained VT/VF/SCA & $49(54)$ & $10(56)$ & $39(54)$ & 1.0 \\
\hline "Definite" ARVD & $77(86)$ & $18(100)$ & $59(82)$ & 0.06 \\
\hline Amiodarone & $14(16)$ & $3(17)$ & $11(15)$ & 1.0 \\
\hline$\beta$-blocker & $43(48)$ & $10(56)$ & $33(46)$ & 0.6 \\
\hline Sotalol & $13(14)$ & $4(22)$ & $9(13)$ & 0.28 \\
\hline Other antiarrhythmic therapy & $7(8)$ & $2(11)$ & $5(7)$ & 0.63 \\
\hline
\end{tabular}

Values are mean \pm standard deviation, median with interquartile range and $\mathrm{n}(\%)$.

Definite, a definite diagnosis of ARVD according to the 2010 Task Force Criteria.

BP, blood pressure; BSA, body surface area; RV, right ventricular; SCA, sudden cardiac arrest; VF, ventricular fibrillation; VT, ventricular tachycardia.

\begin{tabular}{|c|c|c|c|c|}
\hline Characteristic & $\begin{array}{l}\text { All patients } \\
\quad(n=90)\end{array}$ & $\begin{array}{l}\text { Atrial arrhythmia } \\
\qquad(n=18)\end{array}$ & $\begin{array}{l}\text { No atrial arrhythmia } \\
\qquad(\mathrm{n}=72)\end{array}$ & $P$ value \\
\hline RR interval (ms) & $954 \pm 234$ & $874 \pm 250$ & $974 \pm 227$ & 0.1 \\
\hline$P Q$ interval (ms) & $166(147-184)$ & $182(158-198)$ & $165(147-182)$ & 0.11 \\
\hline $\mathrm{P}$ max duration (ms) & $108 \pm 19$ & $104 \pm 20$ & $108 \pm 18$ & 0.46 \\
\hline $\mathrm{P}$ dispersion (ms) & $38(29-51)$ & $36(24-45)$ & $40(30-52)$ & 0.35 \\
\hline Notched P wave & $11(12)$ & $2(11)$ & $9(13)$ & 1.0 \\
\hline $\mathrm{P}$ pulmonale & $5(6)$ & 0 & $5(7)$ & 0.58 \\
\hline $\mathrm{P}$ mitrale & $8(9)$ & $3(17)$ & $5(7)$ & 0.2 \\
\hline QRS duration (ms) & $111(100-128)$ & $122(101-137)$ & $110(100-125)$ & 0.18 \\
\hline RA short axis/BSA $\left(\mathrm{mm} / \mathrm{m}^{2}\right)$ & $22.1(19.4-26.1)$ & $23.9(22.3-31.1)$ & $21.4(19.2-24.9)$ & 0.016 \\
\hline RA long axis/BSA $\left(\mathrm{mm} / \mathrm{m}^{2}\right)$ & $27.6(24-30.1)$ & $29.5(25.2-33.1)$ & $27(24-29.4)$ & 0.05 \\
\hline $\begin{array}{l}\text { RA dilation (short axis }>25 \mathrm{~mm} / \mathrm{m}^{2} \text { or } \\
\text { long axis } \geq 30 \mathrm{~mm} / \mathrm{m}^{2} \text { ) }\end{array}$ & $34(38)$ & $9(50)$ & $25(35)$ & 0.28 \\
\hline LA long axis/BSA $\left(\mathrm{mm} / \mathrm{m}^{2}\right)$ & $19.5 \pm 3.7$ & $21.1 \pm 3.9$ & $19.0 \pm 3.5$ & 0.04 \\
\hline LA dilation $\left(>23 \mathrm{~mm} / \mathrm{m}^{2}\right)$ & $12(13)$ & $6(33)$ & $6(8)$ & 0.012 \\
\hline RV FAC $(\%)$ & $32(22-42)$ & $21.5(20-25.8)$ & $35(27-42.5)$ & 0.001 \\
\hline RV dysfunction (FAC <33\%) & $47(52)$ & $15(83)$ & $32(44)$ & 0.004 \\
\hline $\operatorname{LVEF}(\%)$ & $59(52-64)$ & $55(49.8-60)$ & $60(52.8-65)$ & 0.038 \\
\hline LV involvement (LVEF <50\%) & $14(16)$ & $4(22)$ & $10(14)$ & 0.47 \\
\hline Moderate/severe TR & $11(12)$ & $5(28)$ & $6(8)$ & 0.04 \\
\hline
\end{tabular}

Values are mean \pm standard deviation, median with interquartile range and $\mathrm{n}(\%)$.

LV, left ventricular; LVEF, left ventricular ejection fraction. Other abbreviations as in Tables 1,2.

all ECGs were enlarged 4-fold. ECG intervals were measured in 2 consecutive sinus beats in each lead; the mean value of the 2 beats was used. If the difference between beats was $>10 \mathrm{~ms}$, then the mean of 3 beats was taken. Each ECG was independently analyzed by 2 experienced readers, each of whom was blinded to the clinical outcome data. Differences in the interpretation of the ECG parameters were adjudicated by a third cardiologist, and a final conclusion was made by consensus. ECG variables were measured according to current practice. ${ }^{13-18}$

TTE

Conventional M-mode, 2-D, and color Doppler echocardio- graphic images were obtained by an experienced cardiologist according to guidelines. ${ }^{19}$ Echocardiographic RV fractional area change (FAC) was calculated as previously reported (Figure $\mathbf{1}$, Table 1). ${ }^{20} \mathrm{FAC}<33 \%$ was considered abnormal. Left ventricular (LV) involvement was considered when LV regional wall motion abnormalities or a reduced ejection fraction (EF; $<50 \%$ by Simpson's biplane method) were present and other causes had been excluded. ${ }^{20}$ Atrial dimensions were measured as described in Table 1. RA short-axis dimension $>25 \mathrm{~mm} / \mathrm{m}^{2}$ or RA long-axis dimension $\geq 30 \mathrm{~mm} / \mathrm{m}^{2}$, and LA dimension $>23 \mathrm{~mm} / \mathrm{m}^{2}$ were considered abnormal in accordance with previous literature. ${ }^{19,21}$ The degree of tricuspid regurgitation was determined 

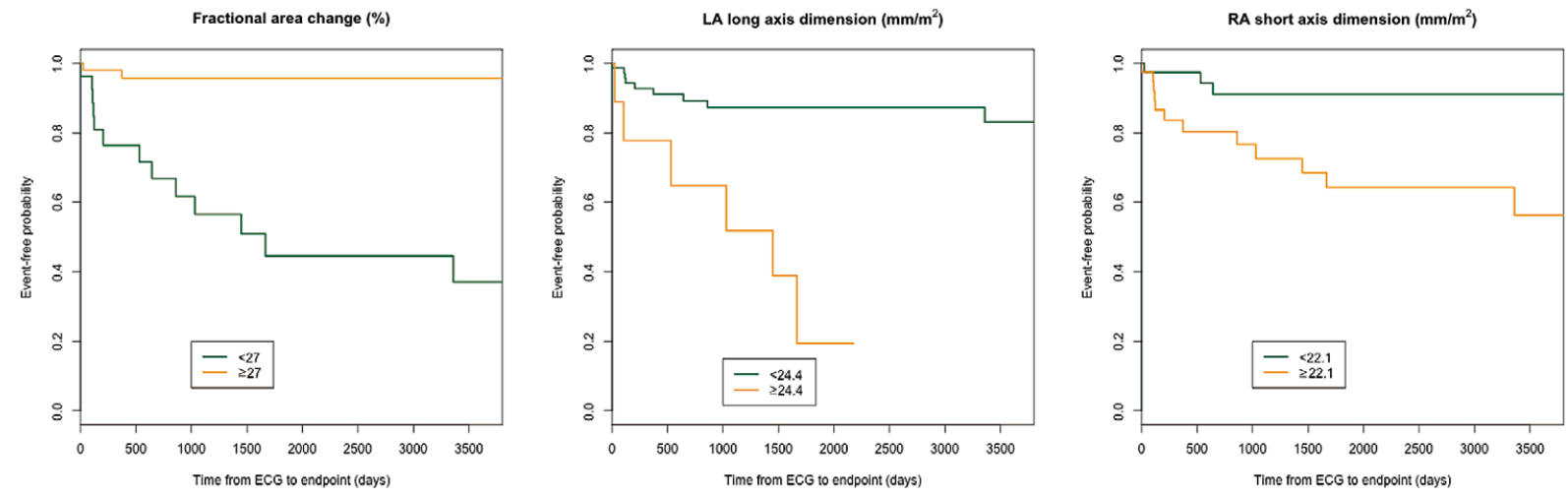

Time from study inclusion to atrial fibrillation/flutter in days

\begin{tabular}{lllll}
\cline { 2 - 4 } days & 0 & 2000 & 4000 & 6000 \\
\cline { 2 - 5 } $\begin{array}{l}\text { patients } \\
\text { at risk }\end{array}$ & 27 & 7 & 4 & 2 \\
& 50 & 26 & 10 & 1 \\
\hline
\end{tabular}

\begin{tabular}{llll}
\hline 0 & 2000 & 4000 & 6000 \\
\hline \hline 38 & 20 & 9 & 3 \\
39 & 13 & 5 & 0 \\
\hline
\end{tabular}

\begin{tabular}{llll}
\hline 0 & 2000 & 4000 & 6000 \\
\hline \hline 71 & 33 & 15 & 3 \\
9 & 1 & 0 & 0 \\
\hline
\end{tabular}

Figure 2. Kaplan-Meier analysis of survival free from atrial arrhythmias [composite of atrial fibrillation $(n=16)$ and atrial flutter $(n=2)$ ] for the time between study inclusion and endpoint. Stratification was performed by RV fractional area change $<27 \%$ and $\geq 27 \%$ (Left, adjusted $P<0.001$ ), LA diameter divided by body surface area of $\geq 24.4 \mathrm{~mm} / \mathrm{m}^{2}$ and $<24.4 \mathrm{~mm} / \mathrm{m}^{2}$ (adjusted $P=0.001$ ) measured with M-mode echocardiography in the parasternal long axis (Middle), and a RA short-axis diameter divided by body surface area $\geq 22.1 \mathrm{~mm} / \mathrm{m}^{2}<22.1 \mathrm{~mm} / \mathrm{m}^{2}$ (adjusted $\mathrm{P}=0.05$ ) measured in the apical 4-chamber view (Right). RA, right atrial; RV, right ventricular.

as none, mild, moderate, or severe. Some of the echocardiographic data from 70 patients used in this study has been reported in a previous study from our group. ${ }^{22}$

\section{Outcome Measures}

Follow-up for outcome data was performed by hospital chart review, including clinical visits, 12-lead ECGs, Holter ECGs, and implantable cardioverter-defibrillator (ICD) interrogations with stored electrograms (EGMs). ${ }^{23}$ Inappropriate ICD therapy was defined as previously described. ${ }^{10}$ For the purpose of this study, atrial arrhythmia was defined as AF and/or AFl that lasted $\geq 30$ s. Episodes lasting $<30$ s were only included if they were terminated by an ICD shock. AF-AFl only occurring during electrophysiological studies was excluded. When atrial arrhythmia was not diagnosed by 12-lead or Holter-ECG, discrimination between atrial arrhythmia and ventricular tachycardia was based on stored EGMs using standard diagnostic criteria, including regularity of ventricular arrhythmia, EGM morphology, and the relationship of atrial and ventricular EGMs. ${ }^{5,24}$ Cardiac death was defined as sudden cardiac death or death due to terminal heart failure. The influence of ECG and TTE parameters on long-term clinical outcome was compared in 2 patient groups: (1) those with atrial arrhythmia (composite of AF-AFl) and (2) all other patients. For KaplanMeier and Cox regression analyses, time from study inclusion to the occurrence of first episode of AF-AFl was the event of interest.

\section{Statistical Analysis}

Continuous variables are presented as mean \pm SD or median (with interquartile range, IQR), and compared using a 2-sided t-test or Mann-Whitney U-test, as appropriate. Categorical variables are reported as frequency (percentage) and compared between groups by Fisher's exact test. Pearson's or Spearman's correlation was carried out to analyze correlations between TTE and cardiac magnetic resonance (CMR) parameters, as appropriate. Cut-off points for continuous variables that maximized the difference in survival free from AF-AFl were determined. This was done by minimizing the P-value of the log-rank test, and then correcting for multiple testing. Survival free from AF-AFl was estimated using the Kaplan-Meier method, and differences between groups were assessed with the log-rank test. Baseline variables associated with a significantly altered hazard for atrial arrhythmia were identified by univariable Cox regression analysis. The predictive discrimination of FAC, LA and RA dimensions was measured using Harrell's c-index, which accounts for censored measurements. We mainly focused on the electrocardiographic and echocardiographic data obtained during initial assessment of patients with ARVD that could be important for predicting AF-AFl during follow-up. To evaluate the effects of classical risk factors of AF-AFl in the general population, we included age, sex, arterial hypertension, coronary artery disease, and body mass index in our univariable model. The initial clinical assessment will guide the physician in choosing the appropriate therapy for each individual patient based on the risk for AF-AFl. As in most clinical situations, it is not appropriate to wait for an assessment of electrocardiographic and echocardiographic changes to evaluate the patient's risk for AF-AFl, so we have not used the change in parameters over time in predicting this endpoint. A 2 -sided P-value $\leq 0.05$ was considered significant. Statistical analysis was performed using $\mathrm{R}$ programming language 


\begin{tabular}{|c|c|c|}
\hline \multirow{2}{*}{ Variable } & \multicolumn{2}{|c|}{ Univariable analysis } \\
\hline & HR (95\% Cl) & $P$ value \\
\hline $\mathrm{FAC} \geq 27 \%$ & $0.099(0.03-0.35)$ & $<0.001$ \\
\hline$F A C \geq 33 \%$ & $0.26(0.08-0.91)$ & 0.036 \\
\hline FAC (\%) per unit decrease & $1.09(1.03-1.14)$ & 0.003 \\
\hline $\mathrm{LA} \geq 24.4 \mathrm{~mm} / \mathrm{m}^{2}$ (long axis) & $7.03(2.43-20.34)$ & $<0.001$ \\
\hline $\mathrm{LA}\left(\mathrm{mm} / \mathrm{m}^{2}\right)$ per unit increase (long axis) & $1.15(1.01-1.31)$ & 0.031 \\
\hline $\mathrm{RA} \geq 22.1 \mathrm{~mm} / \mathrm{m}^{2}$ (short axis) & $5.47(1.55-19.37)$ & 0.008 \\
\hline $\mathrm{RA}\left(\mathrm{mm} / \mathrm{m}^{2}\right)$ per unit increase (short axis) & $1.08(1.02-1.15)$ & 0.013 \\
\hline $\mathrm{P}$ mitrale & $3.37(0.92-12.4)$ & 0.067 \\
\hline Age at inclusion (per year increase) & $1.02(0.99-1.06)$ & 0.13 \\
\hline Moderate/severe TR & $2.07(0.72-5.97)$ & 0.18 \\
\hline LV involvement & $1.95(0.63-6.02)$ & 0.25 \\
\hline$\beta$-blocker therapy & $1.35(0.53-3.44)$ & 0.53 \\
\hline Female sex & $1.32(0.51-3.41)$ & 0.57 \\
\hline Presence of CAD & $2.03(0.46-8.91)$ & 0.35 \\
\hline Body mass index $\left(\mathrm{kg} / \mathrm{m}^{2}\right)$ & $0.99(0.91-1.07)$ & 0.76 \\
\hline Previous sustained VT/VF/SCA & $0.89(0.34-2.31)$ & 0.81 \\
\hline Notched P wave & $1.2(0.27-5.44)$ & 0.81 \\
\hline Amiodarone therapy & $1.1(0.31-3.95)$ & 0.88 \\
\hline Presence of arterial hypertension & $0.91(0.26-3.17)$ & 0.88 \\
\hline
\end{tabular}

$P$ values calculated by univariable Cox regression.

$\mathrm{AF}-\mathrm{AFI}$, atrial fibrillation and atrial flutter; $\mathrm{CAD}$, coronary artery disease; $\mathrm{Cl}$, confidence interval; $\mathrm{HR}$, hazard ratio. Other abbreviations as in Tables 1-3.

(R Development Core Team, 2009) and GraphPad Prism 5 (GraphPad Software Inc, La Jolla, CA, USA).

\section{Results}

\section{Study Population}

Patient demographic data, baseline characteristics, and ECG and TTE variables are summarized in Tables 2,3: 88 patients were index patients, and 2 were family members. ARVD was classified as definite in $77(85 \%)$ patients, and borderline in 13 $(15 \%)$ patients. In total, 57 (63\%) patients had an ICD, 38 with a single-chamber device (VVI), 18 with a dual-chamber device (DDD), and 1 patient with a cardiac resynchronization device. Arterial hypertension was present in $17(19 \%)$, and coronary artery disease in $6(7 \%)$ patients.

\section{Prevalence of AF-AFI}

During a median follow-up of 5.8 years (IQR 2.0-10.4 years), $18(20 \%)$ patients experienced the composite endpoint (AF $\mathrm{n}=16 / 18$ [88\%], AFl $\mathrm{n}=2 / 18$ [12\%]). Time from study inclusion to last patient contact was not significantly different between those with and without the composite endpoint (median 7.3, IQR 2.5-9.8 years vs. 5.3, IQR 1.7-10.6 years, $\mathrm{P}=0.48$ ). Mean age at the time of the composite endpoint was $50 \pm 13$ years. Median time from study inclusion to atrial arrhythmia was 11.7 months (IQR 3.7-33 months). AF-AFl was paroxysmal in all but 1 patient; 12 patients with AF-AFl also suffered from sustained ventricular arrhythmia: in 7 of them, AF-AFl occurred prior to the first documented sustained ventricular event, while in 4 patients this occurred afterwards, and in 1 patient on the same day. The median $\mathrm{CHA}_{2} \mathrm{DS}_{2}-\mathrm{VASc}$ score of all patients with AF-AFl was 1 (range 0-4; mean 1.1), with 11 individuals recording a score $\geq 1(61 \%)$. Oral anticoagulation was prescribed in 9 patients and aspirin in 1 patient. No adverse events related to anticoagulation were recorded; 3 patients with AF suffered from stroke $(\mathrm{n}=1) /$ transitory ischemic attack (TIA, $n=1) / o t h e r$ peripheral embolism $(n=1)\left(\mathrm{CHA}_{2} \mathrm{DS}_{2}-\mathrm{VASc}\right.$ scores of 1,4 , and 3 , respectively), and stroke $(n=1) / T I A(n=1)$ was documented in 2 patients $\left(\mathrm{CHA}_{2} \mathrm{DS}_{2}-\mathrm{VASc}\right.$ scores of 4 and 0 ) without AF-AFl (17\% vs. 3\%, P=0.05). Successful electrical cardioversion was performed in 1 patient with $\mathrm{AF}$, and successful catheter ablation of the cavotricuspid isthmus was performed in 2 patients with $\mathrm{AFl}$, one of whom later developed AF. Catheter ablation of AF was not performed in any of those 18 patients. Of the patients in whom the initial arrhythmia was $\mathrm{AF}(\mathrm{n}=16), 2$ also experienced $\mathrm{AFl}$ during follow-up.

\section{Predictors of AF-AFI}

Complete echocardiographic data sets were available for 77 (86\%) patients in whom ECG analysis was performed (Table 3). Kaplan-Meier plots revealed that a reduced RV FAC and echocardiographic LA and RA dilation were significantly associated with lower survival free from atrial arrhythmia (Figure 2). For RV FAC, the best cut-off to predict atrial arrhythmias was $<27 \%$, for LA dimension $\geq 24.4 \mathrm{~mm} / \mathrm{m}^{2}$ (measured in PLAX), and for RA dimension $\geq 22.1 \mathrm{~mm} / \mathrm{m}^{2}$ measured in the apical 4-chamber view (short axis). Consistent with this observation, the Harrell's c-index for FAC 27\%, LA dimension $24.4 \mathrm{~mm} / \mathrm{m}^{2}$ and RA short-axis dimension $22.1 \mathrm{~mm} / \mathrm{m}^{2}$ equaled $0.75,0.64$ and 0.67 , respectively. In line with these analyses, a reduced FAC, LA and RA dilation were identified as significant univariable predictors increasing the hazard ratio (HR) for the outcome event. In accordance with echocardiographic LA dilation, $\mathrm{P}$ mitrale more than tripled the hazard for atrial arrhythmias (HR 3.37, 95\% confidence interval 0.92-12.36, Table 4). Other variables such as LV involvement, degree of 
tricuspid regurgitation, use of antiarrhythmic medication and $\beta$-blockers, and a spontaneous episode of sustained ventricular tachycardia or ventricular fibrillation, and also the classical risk factors of AF-AFl in the general population such as arterial hypertension, coronary artery disease, sex, age, and BMI were not associated with a significantly altered hazard for AF$\mathrm{AFl}$ on univariable analysis. CMR data were available and analyzed for 21 patients, showing a median RVEF of $45 \%$ (IQR 35-50.5), and a median RV end-diastolic volume index (RVEDVI) of $106.1 \mathrm{ml} / \mathrm{m}^{2}$ (IQR 92-135.2). Atrial dimensions were measured in the CMR 4-chamber view, and yielded a median RA area of $23 \mathrm{~cm}^{2}$ (IQR 18-36), and a median LA area of $22 \mathrm{~cm}^{2}$ (IQR 17-24), respectively. Echocardiographic FAC and RV end-diastolic area index (RVEDAI) significantly correlated with RVEF and RVEDVI as determined by CMR, respectively ( $\mathrm{r}=0.48, \mathrm{P}=0.028$ for $\mathrm{FAC}$ vs. RVEF; $\mathrm{r}=0.67$, $\mathrm{P}=0.001$ for RVEDAI vs. RVEDVI). Correlation between the echocardiographic RA short-axis dimension and RA area by CMR showed a trend towards significance $(r=0.6, P=0.07)$.

\section{Inappropriate ICD Shocks Related to AF-AFI}

During follow-up, 5 patients (28\%) with atrial arrhythmias suffered from inappropriate ICD shocks because of AF-AFl with rapid ventricular conduction. Of them, 3 patients $(n=3 / 5,60 \%)$ had a single-chamber ICD. In contrast, 4 patients without AF$\mathrm{AFl}$ experienced inappropriate shocks during follow-up (36\% vs. $9 \%, \mathrm{P}=0.03)$. Distribution of single-chamber $(\mathrm{n}=4)$ and dualchamber $(n=5)$ ICDs was similar among the patients with AF$\mathrm{AFl}$ who did not receive inappropriate shocks during follow-up.

\section{Association of AF-AFI and Heart Transplantation/Cardiac Death}

Of the 90 patients included in this study, 6 patients underwent heart transplantation, and 3 died of end-stage heart failure $(\mathrm{n}=9 / 90,10 \%)$. AF-AFl was previously documented in 5 of these 9 patients, which was significantly more prevalent in this patient group with an adverse outcome compared with the remaining patients ( $56 \%$ vs. $16 \%, \mathrm{P}=0.014)$.

\section{Discussion}

The results of this observational long-term study suggest that $\mathrm{AF}-\mathrm{AFl}$ are common, and that their presence is associated with an adverse clinical outcome (inappropriate shocks, heart transplantation, cardiac death) in patients with ARVD. Echocardiographic evidence of reduced RV function and atrial dilation helps to identify ARVD patients at increased risk for the development of these atrial arrhythmias.

Supraventricular arrhythmias have been associated with ARVD since the initial description of this cardiomyopathy. ${ }^{25}$ Previous groups have reported a prevalence rate between $4 \%$ and $42 \% .^{5,8-10,26}$ Early small-scale studies suggested that the presence of tricuspid regurgitation and atrial enlargement were associated with the development of atrial arrhythmias. A recent large-scale retrospective study has mainly confirmed those findings. ${ }^{10}$ However, atrial dilation was not well defined in any of these studies, and none of them has investigated the role of 12-lead ECG and RV function in predicting atrial arrhythmias.

\section{Predictors of AF-AFI}

There is limited data about the risk factors for AF-AFl in patients with ARVD. ${ }^{5,8-10}$ Except for the study by Camm et al, ${ }^{10}$ earlier studies were limited by small sample sizes and inclusion of patients with advanced ARVD. ${ }^{5,8,9}$ Although Chu et al demonstrated an association between RV dimensions and atri- al arrhythmias in ARVD, ${ }^{5}$ our study is the first to demonstrate an association between reduced $\mathrm{RV}$ function and $\mathrm{AF}-\mathrm{AFl}$ in this patient population. Importantly, a cut-off of $<27 \%$ for FAC, $\geq 24.4 \mathrm{~mm} / \mathrm{m}^{2}$ for LA dimensions measured with M-mode in the PLAX, and a RA short-axis dimension $\geq 22.1 \mathrm{~mm} / \mathrm{m}^{2}$ measured in the apical 4-chamber view best identified ARVD patients at increased risk for AF-AFl. In line with prior studies, the presence of moderate-to-severe tricuspid regurgitation increased the risk for AF-AFl in our cohort as well, although this association was not significant. Hence, our study extends those previous findings by demonstrating an association between RV function, a hallmark of ARVD, and AF-AFl, and by providing cut-off values for echocardiographic variables that may help to predict AF-AFl in these patients. Although in our cohort LVEF was generally lower in patients with AF-AFl, LV involvement was not associated with atrial arrhythmias in this our study, which corresponds well with the previous data from Chu et al, ${ }^{5}$ and could possibly be explained by the fact that LV involvement was rare (16\% in our cohort), or that its current definition has a rather low sensitivity to detect early forms of LV involvement. We found that despite a rigid ECG analysis protocol, 12-lead ECG was generally less useful than TTE for predicting AF-AFl. The presence of P mitrale was associated with an increased risk for $\mathrm{AF}-\mathrm{AFl}$, with a trend towards statistical significance, in line with the finding that echocardiographic LA dilation constituted a significant predictor. Although the 12-lead surface ECG has been shown to be useful for predicting AF in patients without ARVD, ${ }^{13,27} \mathrm{ECG}$ parameters of atrial dilation have generally been limited by poor sensitivity despite good specificity. ${ }^{28}$ Although we used ECG definitions for atrial enlargement that have been validated by CMR, because of its high accuracy in volumetric assessment of cardiac chamber sizes, ${ }^{14}$ we were unable to identify any ECG variable that significantly predicted atrial arrhythmia in our ARVD cohort.

\section{Classical Risk Factors of AF-AFI}

Patients with AF-AFl were older than those without these arrhythmias. ${ }^{10}$ Accordingly, age increased the HR for AF-AFl, but was not a significant predictor in our univariable Cox model. The mean age of 50 years at last follow-up, with an AF-AFl prevalence of $20 \%$ in this cohort confirms a relatively high disease burden in an age group with a disease prevalence of usually around $0.5 \% .^{7}$ In contrast to the study by Camm et al ${ }^{10}$ and some population-based studies, ${ }^{29}$ male sex did not increase the risk for $\mathrm{AF}-\mathrm{AFl}$ in our cohort. Of note, other classical risk factors such as arterial hypertension, coronary artery disease, and BMI also did not predict AF-AFl. Our findings are in line with data from Chu et $\mathrm{al}^{5}$ and imply that reduced RV function, atrial dilation, and disease stage seem to be more important for assessing the risk of AF-AFl in ARVD patients rather than the classical risk factors.

\section{Pathophysiology of Atrial Arrhythmias in ARVD}

The causes of atrial arrhythmias in ARVD are not well understood. Although arterial hypertension and atrial dilation are known risk factors for $\mathrm{AF}$ in the general population, ${ }^{30,31}$ arterial hypertension was not significantly associated with AF-AFl in patients with ARVD in the current or previous studies. This may be related to the fact that AF-AFl manifests earlier in patients with ARVD. Furthermore, ARVD patients are often engaged in endurance sports and take blood pressure-lowering medication that may protect them from developing arterial hypertension. ${ }^{32}$ We have shown that biatrial dilation, and most importantly reduced RV function, are associated with AF-AFl. 
To what extent our findings can explain the full pathophysiology of atrial arrhythmia in ARVD is unclear. Further research investigating the role of pathogenic mutations, fibrofatty infiltration, endurance training, and electrical propagation in the atria of these patients is certainly needed.

\section{Arrhythmia Detection and Clinical Implications}

AF-AFl in patients with ARVD is often not paid enough attention. We were able to show that AF is very common in this rather young population adverse outcomes. Only patients with definite ARVD experienced AF-AFl during follow-up. Of note, $\mathrm{AF}-\mathrm{AFl}$ was not associated with the presence of sustained ventricular arrhythmias. However, our data are in line with previous data demonstrating that $\mathrm{AF}-\mathrm{AFl}$ is associated with increased morbidity and adverse outcomes in this population. With regard to this, cardiac death and heart transplantation because of end-stage heart failure were more prevalent in the group with AF-AFl. ${ }^{10}$ Thus, it is very important to identify high-risk patients before AF-AFl occurs. The echocardiographic variables and cut-offs found in this study can help to identify such patients, and to adjust therapeutic interventions and individual arrhythmia monitoring. During follow-up, $36 \%$ of the present patients with AF-AFl suffered from inappropriate ICD shocks despite taking $\beta$-blockers or amiodarone, and the majority of these patients had a single-chamber ICD. Therefore, our results may help in the decision-making process of whether a patient should receive a single- or dualchamber ICD (the latter preferentially in older patients and an increased risk for $\mathrm{AF}-\mathrm{AFl}$ ) and may affect ICD programming such as the enhancement of SVT detection algorithms in these patients. Serial ECGs, Holter ECGs and comprehensive ICD interrogations seem to be pivotal in detecting atrial arrhythmias in this population. Given the fact that AF-AFl was paroxysmal in $94 \%$ of patients, atrial arrhythmias may often go undetected. Moreover, based on our results therapeutic recommendations such as a higher degree of exercise restriction and enhanced control of other risk factors such as hypertension (eg, with angiotensin-converting enzyme inhibitors and potassiumsparing diuretics) and obesity may be warranted in individuals with ARVD and an increased risk for AF-AFl.

\section{Study Limitations}

This study is limited by its observational nature. All patients were recruited in tertiary-care centers, which may reflect a referral bias, and indicate the need for confirmation of our results in lower risk ARVD populations. However, these limitations are inherent to any orphan disease registry, and likely very well reflect the way these patients are managed in daily clinical practice. Because our ARVD program is emerging, we currently do not have sufficient genetic data, so we may have missed important genotype-phenotype correlations that could be associated with our findings. 33,34

\section{Conclusions}

This observational long-term study suggests that AF/AFl are common in patients with ARVD, and associated with inappropriate ICD shocks, heart transplantation, and cardiac death. Echocardiographic evidence of reduced RV function and atrial dilation helps to identify ARVD patients at increased risk of developing AF/AFl.

\section{Acknowledgments}

This work and the Zurich ARVC/D Program are supported by a grant from the Georg and Bertha Schwyzer-Winiker Foundation, Zurich, Switzerland.

\section{Disclosures}

Conflicts of Interest: Ardan M. Saguner received educational grants from Biotronik, Boston Scientific, St. Jude Medical and Sorin. Sabrina Ganahl: None. Andrea Kraus: None. Samuel H. Baldinger received educational grants from Boston Scientific. Argelia Medeiros-Domingo: None. Arhan R. Saguner: None. Stephan A. Mueller-Burri received educational grants from Biotronik, Boston Scientific, Medtronic, and St. Jude Medical, and consultant speaker fees from Sorin. Thomas Wolber: None. Laurent M. Haegeli: None. Nazmi Krasniqi received consultant and/or speaker fees from Boston Scientific and educational grants from Biotronik, Medtronic and St. Jude Medical. Felix C. Tanner: None. Jan Steffel received consultant and/or speaker fees from Biotronik, Biosense Webster, Medtronic, Sorin and St. Jude Medical, and is co-director of CorXL LLC. Corinna Brunckhorst: None. Firat Duru received honoraria and grants from Biotronik, Medtronic, Sorin and St. Jude Medical.

\section{References}

1. Fressart V, Duthoit G, Donal E, Probst V, Deharo JC, Chevalier P, et al. Desmosomal gene analysis in arrhythmogenic right ventricular dysplasia/cardiomyopathy: Spectrum of mutations and clinical impact in practice. Europace 2010; 12: 861-868.

2. Nava A, Thiene G, Canciani B, Scognamiglio R, Daliento L, Buja $\mathrm{G}$, et al. Familial occurrence of right ventricular dysplasia: A study involving nine families. J Am Coll Cardiol 1988; 12: 1222-1228.

3. Zhang M, Tavora F, Oliveira JB, Li L, Franco M, Fowler D, et al. PKP2 mutations in sudden death from arrhythmogenic right ventricular cardiomyopathy (ARVC) and sudden unexpected death with negative autopsy (SUDNA). Circ J 2012; 76: 189-194.

4. Kim C, Wong J, Wen J, Wang S, Wang C, Spiering S, et al. Studying arrhythmogenic right ventricular dysplasia with patient-specific iPSCs. Nature 2013; 494: 105-110.

5. Chu AF, Zado E, Marchlinski FE. Atrial arrhythmias in patients with arrhythmogenic right ventricular cardiomyopathy/dysplasia and ventricular tachycardia. Am J Cardiol 2010; 106: 720-722.

6. Wolf PA, Abbott RD, Kannel WB. Atrial fibrillation as an independent risk factor for stroke: The Framingham Study. Stroke 1991; 22: 983-988.

7. Benjamin EJ, Wolf PA, D'Agostino RB, Silbershatz H, Kannel WB, Levy D. Impact of atrial fibrillation on the risk of death: The Framingham Heart Study. Circulation 1998; 98: 946-952.

8. Tonet JL, Castro-Miranda R, Iwa T, Poulain F, Frank R, Fontaine $\mathrm{GH}$. Frequency of supraventricular tachyarrhythmias in arrhythmogenic right ventricular dysplasia. Am J Cardiol 1991; 67: 1153.

9. Brembilla-Perrot B, Jacquemin L, Houplon P, Houriez P, Beurrier $\mathrm{D}$, Berder $\mathrm{V}$, et al. Increased atrial vulnerability in arrhythmogenic right ventricular disease. Am Heart J 1998; 135: 748-754.

10. Camm CF, James CA, Tichnell C, Murray B, Bhonsale A, te Riele AS, et al. Prevalence of atrial arrhythmias in arrhythmogenic right ventricular dysplasia/cardiomyopathy. Heart Rhythm 2013; 10: 1661 1668.

11. Marcus FI, McKenna WJ, Sherrill D, Basso C, Bauce B, Bluemke DA, et al. Diagnosis of arrhythmogenic right ventricular cardiomyopathy/ dysplasia: Proposed modification of the Task Force Criteria. Eur Heart $J$ 2010; 31: 806-814.

12. Roten L, Derval N, Sacher F, Pascale P, Scherr D, Komatsu Y, et al. Heterogeneous response of J-wave syndromes to beta-adrenergic stimulation. Heart Rhythm 2012; 9: 1970-1976.

13. Dilaveris PE, Gialafos EJ, Sideris SK, Theopistou AM, Andrikopoulos GK, Kyriakidis M, et al. Simple electrocardiographic markers for the prediction of paroxysmal idiopathic atrial fibrillation. Am Heart J 1998; 135: $733-738$.

14. Tsao CW, Josephson ME, Hauser TH, O'Halloran TD, Agarwal A, Manning WJ, et al. Accuracy of electrocardiographic criteria for atrial enlargement: Validation with cardiovascular magnetic resonance. J Cardiovasc Magn Reson 2008; 10: 7.

15. Surawicz B, Childers R, Deal BJ, Gettes LS, Bailey JJ, Gorgels A, et al. AHA/ACCF/HRS recommendations for the standardization and interpretation of the electrocardiogram. Part III: Intraventricular conduction disturbances: A scientific statement from the American Heart Association Electrocardiography and Arrhythmias Committee, Council on Clinical Cardiology; the American College of Cardiology Foundation; and the Heart Rhythm Society. Endorsed by the International Society for Computerized Electrocardiology. J Am Coll Cardiol 2009; 53: 976-981.

16. Amasyali B, Kose S, Aytemir K, Kilic A, Turhan H, Celik T, et al. $\mathrm{P}$ wave dispersion predicts recurrence of paroxysmal atrial fibrillation in patients with atrioventricular nodal reentrant tachycardia treated with radiofrequency catheter ablation. Ann Noninvasive Elec- 
trocardiol 2006; 11: 263-270.

17. Namdar M, Steffel J, Vidovic M, Brunckhorst CB, Holzmeister J, Luscher TF, et al. Electrocardiographic changes in early recognition of Fabry disease. Heart 2011; 97: 485-490.

18. De Bacquer D, Willekens J, De Backer G. Long-term prognostic value of p-wave characteristics for the development of atrial fibrillation in subjects aged 55 to 74 years at baseline. Am J Cardiol 2007; 100: $850-854$.

19. Lang RM, Bierig M, Devereux RB, Flachskampf FA, Foster E, Pellikka PA, et al. Recommendations for chamber quantification. Eur J Echocardiogr 2006; 7: 79-108.

20. Lemola K, Brunckhorst C, Helfenstein U, Oechslin E, Jenni R, Duru F. Predictors of adverse outcome in patients with arrhythmogenic right ventricular dysplasia/cardiomyopathy: Long term experience of a tertiary care centre. Heart 2005; 91: 1167-1172.

21. D’Oronzio U, Senn O, Biaggi P, Gruner C, Jenni R, Tanner FC, et al. Right heart assessment by echocardiography: Gender and body size matters. J Am Soc Echocardiogr 2012; 25: 1251-1258.

22. Saguner AM, Vecchiati A, Baldinger SH, Rueger S, MedeirosDomingo A, Mueller-Burri AS, et al. Different prognostic value of functional right ventricular parameters in arrhythmogenic right ventricular cardiomyopathy/dysplasia. Circ Cardiovasc Imaging 2014; 7: $230-239$.

23. Saguner AM, Medeiros-Domingo A, Schwyzer MA, On CJ, Haegeli LM, Wolber T, et al. Usefulness of inducible ventricular tachycardia to predict long-term adverse outcomes in arrhythmogenic right ventricular cardiomyopathy. Am J Cardiol 2012; 111: 250-257.

24. Grimm W, Flores BF, Marchlinski FE. Electrocardiographically documented unnecessary, spontaneous shocks in 241 patients with implantable cardioverter defibrillators. Pacing Clin Electrophysiol 1992; 15: 1667-1673.

25. Morady F, Shen EN, Scheinman MM. Unusual features of arrhythmogenic right ventricular dysplasia. Am J Cardiol 1984; 53: 639-
640.

26. Jaoude SA, Leclercq JF, Coumel P. Progressive ECG changes in arrhythmogenic right ventricular disease: evidence for an evolving disease. Eur Heart J 1996; 17: 1717-1722.

27. Dogan U, Dogan EA, Tekinalp M, Tokgoz OS, Aribas A, Akilli H, et al. P-wave dispersion for predicting paroxysmal atrial fibrillation in acute ischemic stroke. Int J Med Sci 2012; 9: 108-114.

28. Lee KS, Appleton CP, Lester SJ, Adam TJ, Hurst RT, Moreno CA, et al. Relation of electrocardiographic criteria for left atrial enlargement to two-dimensional echocardiographic left atrial volume measurements. Am J Cardiol 2007; 99: 113-118.

29. Heeringa J, van der Kuip DA, Hofman A, Kors JA, van Herpen G, Stricker BH, et al. Prevalence, incidence and lifetime risk of atrial fibrillation: The Rotterdam study. Eur Heart J 2006; 27: 949-953.

30. Vaziri SM, Larson MG, Benjamin EJ, Levy D. Echocardiographic predictors of nonrheumatic atrial fibrillation. The Framingham Heart Study. Circulation 1994; 89: 724-730.

31. Krahn AD, Manfreda J, Tate RB, Mathewson FA, Cuddy TE. The natural history of atrial fibrillation: Incidence, risk factors, and prognosis in the Manitoba Follow-Up Study. Am J Med 1995; 98: 476484.

32. Brook RD, Appel LJ, Rubenfire M, Ogedegbe G, Bisognano JD, Elliott WJ, et al. Beyond medications and diet: Alternative approaches to lowering blood pressure: A scientific statement from the american heart association. Hypertension 2013; 61: 1360-1383.

33. Nakajima T, Kaneko Y, Irie T, Takahashi R, Kato T, Iijima T, et al. Compound and digenic heterozygosity in desmosome genes as a cause of arrhythmogenic right ventricular cardiomyopathy in Japanese patients. Circ J 2012; 76: 737-743.

34. Ohno S, Nagaoka I, Fukuyama M, Kimura H, Itoh H, Makiyama T, et al. Age-dependent clinical and genetic characteristics in Japanese patients with arrhythmogenic right ventricular cardiomyopathy/dysplasia. Circ J 2013; 77: 1534-1542. 